\title{
Lifestyle Program as a Commercialized Device
}

\author{
Ji-Hee Kim \\ Hankuk University of Foreign Studies, Seoul, South Korea, supring@hanmail.net
}

\begin{abstract}
This study examines the practice of the representation of a lifestyle program that operates as a commercialized device. The main themes of lifestyle program in Korea are travel, interior, cooking, and play a role in penetrating the point of consumption. In particular, the 'Over flower' series which is the subject of this study is continuously exposed to the commercialized flow while it is represented in the context of 'overseas travel'. Therefore, this study attempted to analyze the text of the whole series ( 8 episodes / 64 times) of 'Over flowers' reflected from 2013 until now. Text analysis, one of the qualitative research methods, is an appropriate methodology for analyzing the practice of representation of the program in detail. The research shows that the 'Over flowers' series has commercialized devices that subtly expose advertisements such as sponsors, promotions, and PPLs with low production cost. The 'Over flowers' series is generally advertised in the area with the help of local authorities and provided with a resources screen. In addition, 'Over flowers' series has a commercial discourse, while subtly exposing beverage, rice, canning, water, airline, and travel agency products of ' $\mathrm{CJ}$ ' that is mother company of 'tvN' which is broadcasting 'Over flowers' series, and highlighting clothes and carrier products of the performer. As a result, overseas trips of 'Over flower' series represent the secret logic embodying consumption through consciousness of naturally consciousness of eating and drinking, and desire and craving to escape from everyday life, and recreating the ideal lifestyle.
\end{abstract}

KEYWORDS: Commercial discourse, Consumer culture, Lifestyle program, 'Over flowers' series, Travel abroad

\section{Introduction}

This study attempts to analyze the process of changing lifestyle programs into commercialized devices. Lifestyle programs in Korea are on the theme of travel, interior, and cooking. In the process, the Korean lifestyle program has been exposed to a variety of exposures that can be combined with the point of consumption. In particular, the 'Over flowers' series, which attempted to analyze texts in this study, is constantly exposing commercialized flows under the broad context of 'overseas travel'. The 'Over flowers' series is a lifestyle program that can maximize the cost savings of broadcasters and has become a vehicle to stimulate the desire of a wider consumer by explaining various travel destinations in detail. Beyond the 'Over flowers' series, the popular lifestyle programs currently in Korea are being promoted in a form that blatantly market lifestyle using commercialized flow. Therefore, the researchers recognized that lifestyle and commercialization need specific discussion, and carried on research.

\section{Theoretical discussion}

\section{Excessive commercialization of lifestyle programs}

Television programs have a challenge to meet both audience ratings and advertising revenue. Lifestyle programs are structured to support commercialization because they are produced in an 'economic context'. This is described in detail in the discussion of Lee (2012) about the channel of lifestyle program. Lee (2012) explains why lifestyle programs appear as part of the re-mediation below. "As the professional channels of lifestyle gradually take their place, the development of the material is infinite as well as the wide range of lifestyle, and the production is relatively easy to meet the scarce contents of the digital era. In addition, lifestyle programs have the role of segmenting and specializing the whole area of life and being directly related to consumption. In addition, lifestyle programs stimulate the desire of audience in relation to identities of audience, and these behaviors meet the requirements for marketing the company. 
As a result, lifestyle programs may decide to continue to make compulsory promotions to create a new lifestyle in the process of capital inflow" (Lee 2012, 72-77).

The cost of producing a lifestyle program is measured to be much lower than the cost of the drama. For example, 'The Bugaboo' is about 1 billion Korean won per episode, 'Mr. Sunshine' is about 1.5 billion Korean won per episode, and 'Over flowers' is about 88 million Korean won per episode. In addition, 'Over flowers: Grandfather' is produced by indirect advertisement (PPL) and intermediate advertisement income, and the production cost is much lower than the production cost of the drama. In other words, lifestyle programs are being produced constantly because of high costeffectiveness, while production costs are reduced. This commercialized strategy has become more robust as television has entered the multi-channel era.

Williams (1974) referred to the commercialization of television as a flow. He refers to planned flow in that television is arranged according to the flow at a vertical time by composition, and that the expression 'to watch television' refers to gaining the whole experience, not to watch individual programs. Williams states that when we watch a television program, we experience not only specific programs, but also scenes that appear at intervals between programs and programs (Williams 1974, 145-47). This can be seen as a flow of experience of advertisement between programs and programs in the modern mediascape, as well as program interim advertising. Broadcasts were funded from commercial advertising as advertisement between programs and programs and interim advertising were implemented. As television advertising evolved into various forms such as indirect advertising, interim advertising and advertisement between programs and programs, the programs sponsored by the advertisers are presented in an integrated form as if they were part of the program from the planning stage. This can be seen as a 'flow' that has been planned since the program planning stage. This aspect is more pronounced as competition between broadcasters becomes more serious. Broadcasters plan a strategy of flow so that viewers can be pinned or captured in front of a channel throughout the evening. In other words, television producers have been structured in agreement with advertisers from the earliest stages, systematizing customary forms of acceptance (Williams 1974, 148-54). This systematic flow is evolving as the media develops. Currently, program interim advertising and advertising between programs and programs are deliberately combined, and a lifestyle program is being produced as a commercialized device.

This lifestyle program is a commercialized device that can maximize indirect advertising and promotion, and it can be understood that it is mediated within continuous economic dynamism. The lifestyle program shows that the media cost and the re-mediation are constant because the cost of production, the cost-effectiveness, indirect advertisement and promotion are continuously performed and the power of the lifestyle program can be larger than the drama.

\section{Research question and method}

\section{1) Research question}

This study was based on the following research question.

Research question: How does the 'Over flowers' series of lifestyle program stimulate desire for consumption of audience by specifically representing the tendency of commercialization?

The 'Over flowers' series is a program that is broadcast every Friday night at 9:30 pm from 2013. Therefore, it is important to look specifically at how the 'Over flowers' series, which is being broadcast in prime time, can be used as an artistic element in a specific commercialization tendency, and stimulate the desire of the audience by using appropriate flow without irritating factors.

\section{2) Research method}

In order to examine how the 'Over flowers' series represents the naturalization of commercialization, the researcher tried to analyze the text of the entire 'Over flowers' series ( 8 episodes / 64 times). In order to identify the meaning of the 'Over flowers' series as a lifestyle program and to understand its meaning, this study was divided into three series such as three episodes of 'Over flowers: Grandfather', 'Over flowers: Sister' and four episodes 'Over flowers: Youth'. It was analyzed all 64 times for three series of over flowers. It took a lot of time to watch a total of 64 times from the 'Over flowers' series that broadcast 
about 1 hour and 20 minutes to 40 minutes each time through repeated viewing. 'Over flowers' series can imply the characteristics of the lifestyle program as a commercialized device specifically through intertextuality. Text analysis, one of the qualitative research methods, is an appropriate methodology to examine the flow of commercialized lifestyle in the flow of representation.

\section{Research result and discussion}

\section{Commercialization tendency of 'Over flowers' series}

CJ E\&M, a Korean cable television company, is working as a center point for producing large-scale commercialization and consumption through self-production of contents or co-production. Among the channels of CJ E\&M, tvN in Korea created a series of 'Over flowers' and succeeded in the 'Over flowers' series, and then made a various lifestyle programs such as 'Three meals a day', 'Yoon's restaurant', 'The Three musketeers in Island' and so on. This flow created a momentum to accelerate the desire of a distinct life, and was connected with the flow of consumption. Entertainment programs of tvN seem ordinary, but they stimulate the desire of the audience by representing a special lifestyle.

The total 8 episodes of 'Over flowers' series of tvN is represented as a commercialized device with a special lifestyle and consumption. The 'Over flowers' series can be seen as a 'visual media spectacle' that combines broadcast content and travel with celebrities, as well as an explicit 'lifestyle marketing' product. These programs take the typical form of selling a somewhat classy, awe-inspiring, fascinating and fantastic lifestyle of traveling abroad (Kim 2012, 122).

The 'Over flowers' series has attracted consumption by representing the space that can consume exotic emotion, refined space and luxurious taste through atmosphere. The 'Over flowers' series symbolizes the exoticism and special lifestyle of a specific space abroad, allowing audience to get a glimpse of the fantasy and charm of an exotic place, and dreams of a colorful romanticism that transcends cultural boundaries. At its base there is a commercial flow that goes through this series consistently. The 'Over flowers' series has a commercialized device in it that cleverly exposes sponsorship, promotions, PPL products, and intermediate advertisements.

The 'Over flowers' series is generally provided with a resource screen and a travel route with the help of the local Tourism Authority. In this process, the producer introduces overseas with an exotic view, and transfers the tourist destination to the audience in detail, and melts the promotional act of the tourist agency directly in the program. For example, the producer informed the performer who were watching Dubai Mall the news that a staff of Dubai Tourism Agency visited at the 'Over flowers: Grandfather - Greece' section (1 episode, 45:00). The Dubai Tourism Authority said, "Let me know where you want to go for a memorable trip and I will help you. Tell them everything you want." The performers are asking to provide the cost of using Dubai's landmark and the world's tallest building, Burj Khalifa's super-fast elevator The Burj Khalifa's high-speed elevator is the world's longest elevator, rising 10 meters per second, and Dubai's landmark, which takes 45 seconds to the 124-story observatory. The quite expensive cost of going up is 400 dirham per person $(120,000$ Korean won). The Dubai Tourism Authority staff readily accepts the demands of the performers and says that it is an enjoyable trip. This simple episode is a representative point that allows us to recognize that the 'Over flowers' series is a commercial program. That is to say, the producers of 'Over flowers' series are good because they can bring landscape to the screen, the performers can watch landscape for free, and the Dubai Tourism Agency can inform Dubai's potential customers and broadcasts in Korea. There is a sort of collaborative or publicized commercialization strategy. As a result, these promotions illustrate clearly that the lifestyle discourse presented to us by the series 'Over flowers' is working in a thoroughly commercialized strategy and planning.

These points are laid out throughout the 'Over flowers' series. While the 'Over flowers' series combines travel with the celebrities, and various promotions and sponsors cover the production costs, points where in-program and out-of-program and indirect advertisements are exposed are found everywhere. There are exposed various items in the 'Over flowers' series program such as tourism agencies, travel agencies, hotel combine, airlines representing airline VIP rooms and VIP seats, rental cars, apparel companies, luggage companies, drinking water of Lotte company and foods of CJ 
company. The producers of the 'Over flowers' series suggest that the performers should be selected according to their taste by exposing the instant rice they eat. In addition, the producer makes an indirect advertisement with Lee Seo-jin who is the performer making a Kimchi stew when the producer puts a can of Alaskan salmon in CJ Cheiljedang instead of tuna can. In addition, the 'Over flowers' series draws a clear picture of the drinks and water in the camera. In accordance with this program flow, we are influenced by a commercialized flow that has nothing to do with programs such as indirect advertising and interim advertising while accepting a single program.

Raymond Williams summarized this as a program flow. Williams said that flow is a fluid way of communicating unrelated texts, such as advertisements, TV programs, and broadcasters' own promotional materials, into a form of overall experience of watching TV (Williams 1974, 10). The 'Over flowers' series begins with the program involved advertisement of 'Isis' or 'Trevi', explaining the contents of the last episode in frame format for about 30 seconds each time. In addition, in the travel related to the accommodation, the producer advertises a hotel search app called 'Hotel combine', and chooses the accommodation which the sponsor receives, and it represents the place as if it advertises the property. Moreover, the 'Over flowers' series exposes various commercial items such as 'Trevi', 'Hotel combine', Airline, 'Isis', 'Kochujang', 'Salmon Canned', and 'Hatban' in a program. It advertises about 60 seconds of intermediate advertisement 1-3 times and naturally forms a commercialized flow that is independent of the television text.

The 'Over flowers' is a place where airplane tickets, airports, markets with various goods, tourist weather, duty-free shops, travel agency, tourist agency, drinks of CJ company and water of Lotte company are represented naturally. The 'Over flowers' series of travel destinations can be seen as a commercialized device that can show strategic options. In other words, the 'Over flowers' series emphasizes audience to create a lifestyle with leisure through promoting with various partners, and naturally investing time and money. The stories and products of the characters appearing in the series 'Over flowers' have a multi-aura, and are linked to our consciousness and meanings, playing a role in the daily image of modern people, naturally making politicians of consumption.

Currently, the commercialized flow of lifestyle programs is shifting beyond one program to other programs that are similar to the 'Over flowers' series. This can be interpreted as a phenomenon in which the flow referred to by Williams develops in the form of a 'super-flow' in which the flow between programs and programs extends beyond the flow of programs, intermediate advertising, and indirect advertising. Since the series 'Over flowers', broadcasters are planning and producing various programs on the topic of travel and lifestyle. This tendency was maximized as indirect intervention and intermediate intervention in the program became more liberal. The commercialized flow supports the production cost of broadcasters, promotes advertising effects for advertisers, and is delivered almost as it is to audience who are mentally hungry.

The commercial flow of the 'Over flowers' series puts fantasies about the exotic 'Leave abroad' to audience who are tired of life as surplus. The illusion is linked to the context of consumption by inducing the stimulation of the desire of the audience. In other words, the audience searches for overseas travel destinations or purchases overseas travel as a practical act is linked to stimulating desire. For example, it invites us to do the consumption of travel through the advertisement of Trevi of CJ company, and the Isis advertisement of Lotte company. In addition, we showcase museums, art galleries, various performances, and spacious and colorful department stores and markets, and constantly stimulate our desire for exotic life through everyday life.

The 'Over flowers' series of overseas trips is supposed to be an experience that changes not just impulse purchases but life experiences, and plays a role in establishing a new consumption lifestyle practice of YOLO and Carpe Diem. The YOLO is a word written by a backpacker of 'Over flowers: Youth' instead of a greeting. The consumption style of the YOLO that stimulate desire became popular in Korean society. The 'Over flowers' series shows a cultural politics that stimulates consumption by mediating and expressing the 'desire'. 


\section{Conclusion}

The 'Over flowers' series is a program that has the merit of being able to market lifestyle marketing while being a typical broadcast content that sells a deviant, fascinating and fantastic lifestyle. The 'Over flowers' series adopts a representation method that significantly exposes the sponsors to cover production costs. The 'Over flowers' series can lead us through lifestyle programs to the experiences, tastes, and identities of special people's good life in our lives. But we must constantly contemplate the question of how to establish and maintain our identity in the selection and practice of a particular lifestyle, by critically looking at and accepting lifestyle programs that are over-commercialized. Because the lifestyle program has cultural contexts and arguments along with economic contexts, which act as a cultural force that exerts powerful influence on our identity and everyday politics. In this process, lifestyle programs are not simply selling a single product through lifestyle branding, but they are creating a specific lifestyle that combines a style, personality, attitude, worldview, fantasy, value, desire, and then are connected with a certain identity In this context, there is a need to imagine the diverse possibilities of their lives separated from the consumption, away from the lifestyle and the politics of consumption closely associated with lifestyle programs.

\section{Acknowledgments}

The authors are grateful for the support provided by Hankuk University of Foreign Studies for culture studies. This study is based on the first author's doctoral dissertation.

\section{References}

Kim, Young-chan. 2012. More romantic 10-day love trip than movie. Korean Broadcasting Society Cultural Studies Association. In Television after TV: Cultural landscapes of television in the post-network era. Hanu, 115-42.

Lee, Seol-hee. 2012. (The) production process and program characteristics of the Korean lifestyle television. Graduate School of Communication, Yonsei University. 1-260.

Williams, Raymond. 1974. Television: Technology and cultural form. New York: Schacken Books. 1-192. 